\title{
Knowledge Construction by Immersion in Virtual Reality Environments
}

\author{
Luis Alfaro ${ }^{1}$, Claudia Rivera ${ }^{2}$, Jorge Luna-Urquizo ${ }^{3}$, Sofía Alfaro ${ }^{4}$, Francisco Fialho ${ }^{5}$ \\ Universidad Nacional de San Agustín de Arequipa, Peru ${ }^{1,2,3,4}$ \\ Federal University of Santa Catarina - Florianópolis - SC, Brazil ${ }^{5}$
}

\begin{abstract}
The objective of this work is to analyze the potential use of Immersive Virtual Reality technologies as a teaching/learning tool to enrich the organization of the learning environments of educational programs. The study and analysis of human cognition is theoretically based, also considering the Biology of Cognition and various approaches proposed by the theoreticians and researchers of Education Sciences. In the work, the state of the art of immersive technologies is established and their contributions in the construction of the knowledge of cognitive subjects are analyzed as a means for the development of teaching/learning activities, with the support of emerging immersive technologies. The methodology used is that of the bibliographic review of the classic works of printed literature in relation to the Biology of Cognition, and the search in diverse databases of theses and diverse works in universities and digital repositories. The main weakness of the research lies in the fact that the search was limited to documents using English, Spanish, and Portuguese language. To finish, conclusions and recommendations for future work have been established.
\end{abstract}

Keywords-Computer assisted learning environments; immersive technologies; virtual reality; full immersion in virtual reality environments; knowledge construction by immersion in virtual reality

\section{INTRODUCTION}

The conception and design of systems to support learning activities, mediated by resources offered by emerging technologies associated with computing, the Web and other sources which incorporate the possibility of adapting activities, learning objects and interaction to the individual profiles and needs of cognoscent subjects [1], [2], [3], is a research topic that has caught the attention of many research groups focusing on the problem, considering different educational philosophies such as: Instructional planning, social-cultural, social learning, the humanist perspective of education, constructivism and constructionism, which notably influenced the architecture and development of these systems during the different stages of development of this important area of research [4], [5].

Likewise, in the contemporary digital world, finding new ways to involve students in educational processes and activities becomes a great challenge, partly because technologies for domestic use, such as mobile phones, tablets and video game consoles, which are increasingly technologically evolved, have also become very popular resources, since the availability for children and adults is practically unrestricted. The fact of establishing a correlation between the possibilities of its use in educational activities associated with those of the classroom can be even more complex, especially if the technology implemented is less attractive than the technology that cognoscent subjects use at home.
In 1993, Winn [6], based on the works of Maturana [7], [8], [9] and Maturana and Varela [10], [11], stated the need for more research on constructivist education currents in order to use the emerging technologies of Virtual Reality (VR), which offered the possibility of constructing knowledge from direct experiences and not from descriptions of these made by third parties, involving symbolic linguistic, textual or computational mediation which inevitably leads to reflection, and which no longer constitutes an experience of its own. In this research, the works of Maturana and Varela and subsequent authors are analyzed in depth, in order to consider the biology of cognition and different concepts such as: Autopoiesis, interpretation and representation (symbolization), learning, behavior, structural coupling and especially cognition, in order to analyze and understand how cognoscent subjects construct their own knowledge in real and/or virtual environments. The answer to this question would enable a better understanding of the processes and elements associated with human cognition, which will undoubtedly influence the quality of the design and conception of environments, objects and interactions that use immersive technologies for educational purposes.

Likewise, the emerging immersive technologies were developed by the end of 2016 to levels at which it is assumed that they would rapidly penetrate large sectors of the consumer market. It is under that perspective that the development of Augmented and Mixed VR begun, which has been called the "Fourth Wave" of technological innovation and change in the world of computing, the first of these being: PCs, Internet and mobile devices, which have made significant changes in the interaction and communication of people, with an impact that managed to change some aspects of life of the general public.

On the other hand, the discipline of Knowledge Management [12], which establishes different types of knowledge, the Tacit [13] and the explicit [14], each of them with its own attributes and characteristics, can also be considered for the conception and design of objects and interactions of educational environments based on immersive technology.

Finally, the main objective of this work is to investigate and review different approaches that deal with human cognition, especially analyzing the approaches related to learning and the construction of the knowledge of cognoscent subjects and the technological resources offered by immersive technology, in order to establish a correlation between the possibilities of their use in educational activities associated with training and education, envisioning contributing towards the theoretical bases for the conception and design of virtual environments, as well as the use of appropriate objects and interactions.

In this work, Section II explores Human Cognition, Sec- 
tion III deals with and explores immersive technologies, and Section IV explores and analyzes the potential of immersive technologies in the construction of knowledge. Finally, conclusions and recommendations for this work are set out in Section V.

\section{HUMAN COGNITION}

In this section, different approaches to knowledge are explored such as: Human Cognition Biological bases, and other Education Sciences methods considering the views and requirements of these areas, whose action impacts organizations and their systems for human talent formation and capacitation.

\section{A. Biological Bases of Human Cognition}

In this part of the work, we review the concepts in relation to the organization, plasticity, cognition, learning, and language of living beings, according to the proposal of Maturana and Varela [10], and the reformulations of subsequent authors [15].

In accordance with Maturana [16], living systems are autopoietic entities, with a dynamic structure that allows them to interact with each other on a recurring basis, generating a type of structural ontogeny coupling called consensual domain. Throughout this consensual domain living beings interact with their environment, expanding another type of structural coupling called ontogenic adaptation.

The concept of autopoiesis is not tautological, trivial or unscientific, and neither are its derivations, in contrast to the conclusion of a number of authors [15]. An autopoietic machine is organized as a system of production processes of concatenated components in such a way that they produce components that [11]:

1) Regenerate the production processes (relationships) that produce them, through their continuous interactions and transformations; and

2) Constitute the machine as a unit in physical space.

The understanding of the cited authors about the relationship of an organism with its surrounding environment leads to an epistemological problem. In the Western Culture's theories of knowledge, people "store" representations of concepts "in their minds" based on the information collected through perception. The brain somehow stores the facts, uses them to draw conclusions, and updates them based on experience.

So much so, that Maturana and Varela [10] propose that living organisms, including humans, do not simply take information from outside; they react to the "disturbances" of the environment through adaptations of interior structures. The interaction with the environment does not affect the direct addition of "ingredients" in the physical structure of an organism and in symbols in their mental structure; however, it causes qualitative and quantitative changes in these existing structures. The ability to detect disturbances and the kind of structural change they produce is determined through phylogeny, which is understood as the succession of organic forms that are related to the sequence of reproductive relationships of species and through the history of individual adaptations or ontogeny [11], understood as an integral process of development in the direction of an adult state, through which certain structural forms are achieved, allowing the organism to perform functions in accordance with the innate plane that delimits it in relation to the surrounding environment. The ontogeny of a living system is the history of the conservation of its identity through its continued autopoiesis in the physical space.

The interpretation and representation (symbolization) of the world depend on structural adaptations, depending on the interaction with the disturbances of a symbolic and real environment. Humans usually communicate with someone else symbolically. Communication becomes possible through what Maturana [11] call "structural coupling". Organisms of similar species basically possess similar devices to detect disturbances and adapt to them. On top of that, they inhabit similar environments and are likely to find similar disturbances. As a result, the stories of their structural adaptations can be similar. Their structures are "coupled", so communication with other human beings is possible. According to [17], to make communication possible, an approximation must be made in relation to the meanings of the symbols. Negotiation between members of a group about a meaning is established through a compromise [18], and may result in only temporary concordance. Searle [19], having proposed the problem of meaning, focuses on the structure of language acts. In doing so, he proposes the theory of speech acts, developed by Austin [20] who proposes illocutionary acts, whose purpose is to generate consensus and perlocutionary, whose purpose is to provoke an action [21].

Thus, the organism does not construct a representation of the environment, not does it find a proper behavior for it. For it to operate, there is no means nor memory, only a structural dance in the present, which follows a course consistent with the structural dance of the means. Otherwise it disintegrates. The organism's behavior remains adequate only if it retains its adaptive capacity during its interactions, and what an observer saw as "reminded things" consists precisely in that, in the appearance of behaviors that seem appropriate because the organism retains its adaptation against recurring environment disturbances.

For Maturana [9], learning occurs when the behavior of an organism varies during its ontogeny in a manner consistent with the variations of the environment, which it does following a contingent course in its interactions with it. The fact that the nervous system participates in the phenomena of learning is evident when there is interference caused by damage or alteration in this system. The so-called learning phenomena can be described in different ways: "generation of appropriate behavior towards the environment from previous experience", or "acquisition of a new skill as a result of practice", according to which the observer wants to emphasize. It seems that the characterization proposed above is necessary and sufficient to cover all possible cases.

There are two basic perspectives to explain the learning phenomenon:

- According to one perspective, the observer sees the environment as the world where organisms have to exist and act, and that provides the information, data, and meanings required to represent it, and compute the appropriate behaviors that will allow them to survive in it. 
- According to this vision, learning is a process through which an organism obtains information from the environment and builds its representation, storing it in the memory and using it to generate behavior in response to the disturbances of this means. From this point of view, memory consists in finding in memory the representation required to bring adequate answers to the recurrent interactions of the environment.

Under this perspective, the environment is instructive because it specifies in the organism changes of state which, being congruent, constitute a representation of it.

On the other hand, the cited authors see perception as an operation of distinction in which the nervous system, which is an operationally closed system, obtains knowledge [16]. This leads us to a question: How is it that an organism can have knowledge of the world? Learning is not a process of accumulation of environment representations; however, it is a continuous process of behavior transformation going through continuous change in the nervous system's ability to synthesize it. The evocation of representations does not depend on the indefinite retention of a structural invariant which represents an entity (an idea, image or symbol), but on the functional ability of the system to create when there are certain conditions of recurrence, a behavior that meets the recurring demands, classified by the observer as a reactivator [7].

Behavior is not a nervous system invention; it is typical of any unit seen in a medium where a domain of disturbances is specified and maintains its organization as a result of the changes in state that activate it [16]. The usual associations with word conduct are generally actions such as walking, eating, searching, working, etc. Examining all those activities associated with behavior, we see that they relate to movement. The structural coupling is the basis, not only of the changes occurred in the same autopoietic unit or individual throughout their life (learning), but also of those occurring through reproduction (evolution). Indeed, any structural change can be seen as ontogenetic (which occurs during the life of an individual). A genetic mutation is a structural change in a parent that has no direct effect on its state of autopoiesis, until it plays a role in the development of the offspring.

For Maturana [8], "if the observer wishes to discriminate between learned and instinctive behavior, they will discover that in their current realization, both modes are equally determined by the structures of the nervous system and the organism and so, the learned and instinctive behaviors that reside exclusively in the history of the establishment of the structures responsible for them are distinguishable".

The structural coupling [16], generated on the demands of autopoiesis, fulfills the function, naively attributed to having a representation of the world. In the cognitive domain, it is explained how the history of the disturbances of the living being (and its ancestors) leads to the structure that determines them.

- According to another perspective, the observer sees that the behavior of an organism (with its nervous system included) is determined at every moment by its structure, and can only be adapted to the environment if this structure is congruent with that of the environment and its dynamics of change.
- According to this vision, learning is the course of the structural change that the organism follows (including its nervous system) in congruence with the structural changes of the environment, resulting from the reciprocal structural selection that occurs between them during the recurrence of their interactions, retaining their respective identities.

- According to this, there are no instructive interactions, since the medium only selects the structural changes of the organism; it does not specify them.

Maturana [9] is also concerned with understanding the meaning of "cognition" related to the fundamental nature of living beings. This author rejects the metaphor of the treatment of information as the basic element of human cognition, substituting the question of "How does an organism obtain information concerning its environment?" for that of "How does an organism have the structure that allows it to operate adequately in the environment in which it exists?" To answer this question, one must descend to a deeper understanding that cognitive activity is common to all types of life and is determined by the underlying phenomenon of autopoiesis. For the quoted author [7]: "Living systems are cognitive systems and life is a process of cognition. This statement is valid for all organisms with or without a nervous system".

A cognitive system defines a domain of interactions where it can act with relevance to conserving itself, the process of cognition being the actual (inductive) performance or behavior in this domain [7]. A cognitive explanation is related to the relevance of the action for the conservation of autopoiesis and operates in a phenomenological domain, different from the domain of mechanistic behavior determined by the structure.

“... as a result of the structural coupling that takes place throughout history, this takes shape both in the structure of the living nervous system and in the structure of the environment, even though both systems always necessarily operate in the present, by means of processes determined locally as systems determined by the structure ... History is necessary to explain how a given system or phenomenon happens in reality but does not participate in the explanation of the operation of the system or phenomenon in the present" [11].

For observers, it is possible to generate descriptions of the living being's activity in any domain. One of these descriptions, essentially historical, refers to the system's structure and its determination about behavior. No matter how the system becomes what it is, it simply is. At the same time, you can describe (as observers of a history of change within a structure and the environment) the model of interactions through which its structure produces itself and is the relationship of the changes that generate effective actions. This second domain of explanation is called by Maturana [7], "cognitive". This domain refers to the relevance of the mutant structure of the system with an effective behavior for survival.

It is, therefore, in this cognitive domain, that distinctions can be made, based on words such as "intention", "knowledge", and "learning". For Maturana, the cognitive domain is not simply a different (mental) level which provides a mechanistic description of the functioning of an organism, it is the characterization of effective action over time, and essentially 
temporal and historical. One of Maturana's main objectives [8] is to overcome the tendency (imposed by language), to treat mental terms as descriptions or structure of states. In relation to language, this author considers that two organisms when interacting recurrently generate as a consequence a social coupling in which they are reciprocally involved in the realization of their respective autopoiesis. The behaviors that occur in these domains of social links can be communicative and also innate or acquired.

Language, according to [18], as a consensual domain, is a modeling of "mutually guiding behavior" and not a collection of mechanisms in a "user language" or a "romantic" coupling between linguistic behavior and non-linguistic disturbances experienced by organisms. The basic function of language as a behavior-oriented system is not the transmission of information or the description of an independent universe about which one can speak, but the creation of a consensual domain of behavior between systems which interact linguistically through the development of a cooperative domain of interactions [8].

Language is, then, a consensual (conversational) coordination of consensual (individual) coordination of actions. In this context, the "conversation" is the minimum unit of social interaction oriented to the successful execution of actions [22]. According to Winn [6], the work of biologist Maturana has been particularly influential with some constructivists. The "structural coupling" organisms of the same species have basically the same apparatus for detecting and adapting to perturbations. Also, they inhabit similar environments and are likely to encounter the same perturbations. As a result, the history of their structural adaptations will be similar. Their structures are "coupled", which is why we can communicate with other humans but not with bats.

\section{B. Approaches from the perspective of Education Sciences}

In this part of the paper, the authors focus on proposals to explain the development of human autopoietic units, which will be briefly reviewed:

- Behavioral perspectives [23], of learning will contribute to the development of technologies for classroom conduction and instructional realization. Teaching machines, programmed instruction and computerized instruction are among the technologies developed, at least in part, based on these ideas.

- The social learning perspective [24], is driven by behavioral psychologists who considered that operant conditioning offers a limited explanation of learning. They broadened the perspective of learning to include the study of cognitive processes which cannot be observed directly such as expectations, thoughts and beliefs. These psychologists give only a partial explanation of learning and do not adhere to some other important aspects of the subject, such as the social influences of learning.

- Socio-cultural perspective of education: Freire's "Education as a practice of freedom". The ideas of Freire [25] [26] and his followers are located within a sociocultural approach. You cannot speak rigorously of the Freire method, since it is much more than a theory of knowledge and a philosophy of education than a teaching / learning method. The pedagogical theory of this author proposes an education built on the idea of a dialogue between educator and student, where there are always parts of each other in the other. This education could begin with the educator bringing from his world, from his knowledge, from his teaching method, material for educational activities in classrooms based on culture and values. Within this conception and the one regarding the method, there is the basis that anyone educates anyone and that one educates oneself alone.

- Humanistic perspective of education [27], [28]: Some educators sought student-centered teaching. They did not identify themselves as constructivists, although they developed philosophy and constructivist approaches. Among the basic principles of the humanistic approach, there is a belief that each person creates their own reality. The reality they perceive is important to each individual and one person cannot fully know the reality perceived by another.

Humanistic interpretations of motivation emphasize intrinsic sources. Humanistic approaches to education emphasize the importance of feelings, free communication and the values of each student. Humanist education is a philosophy, rather than a compilation of strategies. Many actions that teachers can carry out to support self-esteem and make the center or educational resource or place attractive. One approach associated with humanist education is open schools, whose general research shows that these environments promote creativity, cooperation, selfesteem and social adaptation; however, academic performance is not greater than that of traditional classrooms.

- The perspective of teaching in the biology of love: Various forms of body dynamics, which emerged with the evolutionary history that gave rise to humanity, reappear in the ontogenetic drift of the child's physical and mental development. The various forms of free play of children, which emerge without the influence of adults, are organized on the basis of innate forms of actions in a spontaneous way, which include movements and perceptions, which come from human evolutionary history or phylogeny. The forms of free play are not arbitrary; they are forms of body dynamics that are linked to ancestral behavioral territories, as well as to expressions and connections between the living being and its environment, whose current forms are only transformations of archaic VerdenZöller forms [29]. The future of an organism is never determined by its origin [30]. And it is based on these conceptions that education and the act of "to educate" must be understood and considered. According to these authors, the task of human formation is the foundation of every educational process. Normally, there is no limitation of intelligence as a capacity for consensus; all human beings, except in extreme situations of neurological alterations, are equally intelligent only by communicating through language. Intelligence difficulties arise or result (if there is no neurological damage of any origin) from interference in the biology 
of love. Capacitation is an instrument or path in the realization of the task of formation and education.

- Constructivist perspective: The proposals of Gestalt psychologists such as Piaget [31], Vygotsky [17], Dewey [32], and Bruner Bartlett [33], emphasize the active construction of meaning by the cognitive subject. Emphasis is placed on the creation of meaning and construction of knowledge rather than on the memorization of information. Some of these perspectives also consider the social context as one of the fundamental factors of the knowledge that individuals acquire about themselves and the world. Some theories and studies attempt to explain the processing of information carried out by the human autopoietic unit, of how this represents knowledge in memory, concluding with the individual differences of the cognitive subjects.

- The term constructionism [34] [35], was coined by Papert, becoming one of the contemporary approaches of the Cs. According to this proposal, cognitive subjects carry out constructive tasks and activities to foster creativity and motivate learning in order to facilitate the assimilation of knowledge. It is argued that learning is more effective when it is situated in an activity, rather than being received passively.

The approach involves two types of construction [36]: (i) Cognitive subjects actively construct their knowledge and their experiences in the world, according to the approach of Piaget [31]; (ii) Constructionism adds the idea that it is important for cognitive subjects to be involved in the construction of products of personal significance, in order to build new knowledge.

Finally, Winn [6] points out that virtual immersion makes the construction of knowledge possible based on the direct experiences of the cognitive subject which do not become third-person descriptions, since these experiences do not have elements of symbolic mediation such as text, or the spoken language itself, which inevitably lead to reflection, which will be constituted in the experience of another person. The use of a symbolic system, for the communication to another person about the world we have built, will never allow that person to know our world as we know it.

Some reviewed approaches suggest that intelligence or "plasticity" [7], establishes the capacity of organisms to adapt to their environment; Immersive VR can become one of the emerging technologies that allow experiences in real or virtual environments, making it possible to abstract and synthesize some temporal and spatial variables, that will enable firstperson experiences without requiring symbolic mediation, enabling learning and training involving tacit and explicit knowledge in an original, direct, unique and unforgettable way.

The immersive technologies will be explored further, envisioning their possibilities and contributions in the construction of knowledge of the cognitive subjects.

\section{IMMERSIVE TECHNOLOGIES}

\section{A. Virtual Reality (VR)}

The concept of VR refers to a whole simulated reality which is built with computer systems by using digital formats. Building and visualizing this alternative reality requires hardware and software powerful enough to create a realistic immersive experience (e.g. VR helmets or dedicated glasses and 3D software) [37].

VR [38] is defined as the term used to describe a threedimensional, computer generated environment which can be explored and interacted with by a person. That person becomes part of this virtual world or is immersed within this environment and whilst there, is able to manipulate objects or perform a series of actions. After many years of research and development, VR hardware and software is now widely available to general users, researchers and entrepreneurs. The following types of applications exist in VR: the "Immersive" applications, which enclose the user's audio and visual perception in the virtual world and remove all external information so that the experience is totally immersive. This type of technology is expensive and has some disadvantages, including less determining images, burden and environmental problems concerning simulators [39]. The user who utilizes the total immersion of VR technology has the ability to feel part of the virtual environment. The "Semi-immersives", which consist of experiences in a VR environment using real world attributes, by incorporating computer-generated graphic objects into the simulated virtual scene. Users enter and control this type of system using a mouse, keyboard, interaction styles, lenses and joystick [40]. They allow the user to interact using hands and sometimes glasses or DataGloves. The information displayed, such as text, graphics and images, is highlighted on the transparent screen to allow the user to interact with the real environment.

The "Non-immersive" [41], non-immersive system also called VR desktop (no input devices) is based on the screens that are displayed to the user; this is a window to the virtual world without additional devices such as HMD, and is sometimes called Window on World (WoW) systems [42].

All these alternatives allow the user to live an entirely immersive experience, in a real world or one created by human imagination. Likewise, it is necessary to emphasize that the fact that the user does not observe his own image within the virtual world, subtracts certain realism from the experience in the system, thus limiting his perception of the surrounding reality. Similarly, a certain feeling of dizziness may occur after a prolonged period of use. Current applications are focused on the world of entertainment, education [43], Marketing [44], Knowledge Management, Rehabilitation [45], etc.

"Stereoscopy" is another important feature of immersive $\mathrm{VR}$, since it allows the user to perceive the depth of the object being observed, thus adapting to the natural way of seeing the world around us, which is generated using binocular vision, to create the illusion of perceiving objects in $3 \mathrm{D}$, using two images taken from different positions, thus recreating human vision in 3D [46]. The sensation of depth is a very important element of VR, which gives the user an idea of the position of the objects shown, for which various configurations of lights, shadows, colors, transparencies, and even shapes are 
used [44] [47] [48]. That is why stereoscopy is an excellent alternative to improving depth perception [49]. VR has evolved rapidly in recent decades. In the beginning it could only be used by scientific-military laboratories at an excessive level of implementation cost. Due to the development and process of technological innovation, today, it is possible to have VR technology at moderate costs.

\section{B. 2D, 3D and $R V$ viewing modes}

The different approaches for using representations related to the visualization of information are 2D, 3D and VR [49]. Short descriptions of each of these approaches will be presented below:

- The type of representation using two dimensions is 2D [40]. The graphs are flat, and are notable for their simplicity, precision and clarity in displaying information. Today, a large part of the interfaces are designed for this type of representation. These environments stand out for their precision and clarity in interpreting information. Generally, interaction is traditional and basic interaction techniques such as Zoom and Select are used.

- $\quad$ The type of 3D representation [39], represents an object allowing to visualize the width, length and height, that are assigned in a 2D surface, like a monitor, obtaining a visual perception of three dimensions. To achieve this effect, visual elements for depth such as lights, shadows and perspectives are used. These environments facilitate navigation and are only the result of an extension of interaction techniques in 2D environments, which use visual effects of light and shadow to generate the illusion of volume, but the final representation remains in $2 \mathrm{D}$. The $3 \mathrm{D}$ applications will enhance experiences, even for participants in remote locations, allowing human social interaction [50].

- $\quad$ VR is a technology that allows immersion in a multimodal viewing environment, which also uses stereoscopic images in order to improve depth perception. Thus, it is possible to perceive three dimensions as in the real world. Visualization environments based on VR allow the user to participate in an immersive experience, which allows a different interaction. Some VR interaction techniques include Direct manipulation, in which a virtual hand is available to interact directly with the objects displayed in the system, and the laser beam metaphor, in which a virtual laser pointer is available, with which we can select and manipulate objects and elements.

Fig. 1 shows an example of the three types of environments described above.

\section{Immersion}

A feature of VR, where users are immersed in a simulated virtual world. Psotka [43], states that the fact that a user is placed in a virtual environment, contributes an important emotional factor, which facilitates cognition and improves information retention, because the user has the feeling that they are part of that virtual world. Additionally, immersion

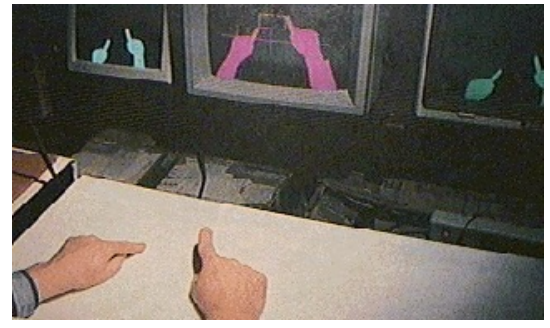

(a) 2D Image. Source: [54]

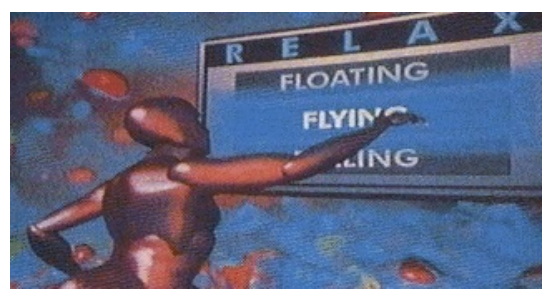

(b) Scanner captures 3D Image. Source: [54]

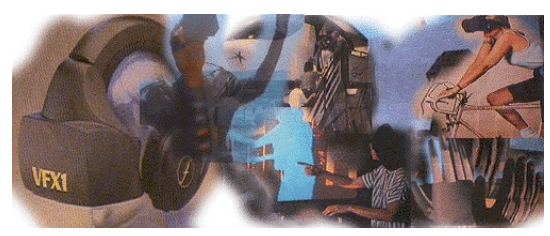

(c) Immersive VR Image Composition. Source: [54]

Fig. 1: Visualization Modes: (a) 2D, (b) 3D y (c) RV

extends the user's range of vision, including travel (which has been very useful in virtual tours) and collaboration (used for manufacturing applications) [41], [51]. For this purpose, immersion was performed through different configurations. For example, a single large screen can be used and an anaglyph lens can be used. Another configuration is that of a CAVE environment consisting of a room with four walls and a projector for each; and another option is the use of a diving helmet or glasses, which have small LCD screens inside, on which images are projected for viewing by the user.

\section{$D$. Immersive $R V$ devices}

Recently, different VR devices have emerged which are mostly manufactured for specific purposes and not for traditional use. Some of them are: "Oculus Rift", "Leap Motion" and "Oculus Go". Fig. 2 shows the main VR viewers on the market. Oculus Rift (Fig. 2(a)) is the first to include a series of improvements such as stereoscopy and low latency in the refresh rate. HoloLens (Fig. 2(b)) experiments with mixing VR and augmented reality, as well as creating the first holographic processor. PlayStation (Fig. 2(c)) was created for entertainment purposes that stand out for their sophisticated design. HTC Vive (Fig. 2(d)) on the other hand, stands out for its good performance and development platform. Gear VR (Fig. 2(e)) uses VR with a wireless approach for which it requires a smartphone. Oculus Go (Fig. 2(f)) is a similar alternative, with the difference that its cost is much lower.

In Table I, these viewers are compared considering the main technical characteristics such as: Screen resolution, re- 


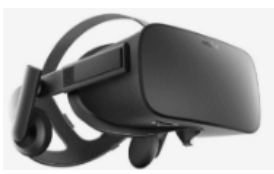

(a)

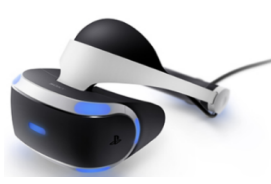

(c)

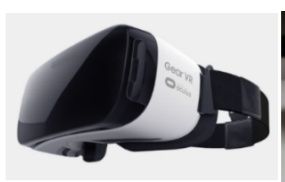

(e)

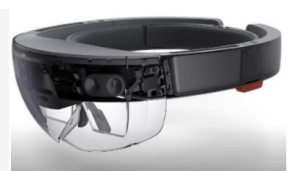

(b)

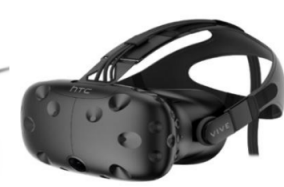

(d)

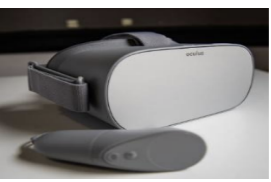

(f)
Fig. 2: Interaction Dispositive Prototypes.

fresh rate, viewing angle and price.

TABLE I. VIEWERS COMPARISON CONSIDERING TECHNICAL ATTRIBUTES AND COST. SOURCE: AdAPTED From [47]

\begin{tabular}{|l|c|c|c|r|}
\hline Visor & Resolution & Refresh rate & Vision angle & Price $\$$ \\
\hline Oculus Rift & $2160 \times 1200$ & $90 \mathrm{~Hz}$. & $110^{\circ}$ & 700.00 \\
\hline Hololens & $1920 \times 1080$ & $120 \mathrm{~Hz}$. & $110^{\circ}$ & $3,000.00$ \\
\hline PlayStation & $1920 \times 1080$ & $120 \mathrm{~Hz}$. & $100^{\circ}$ & 400.00 \\
\hline HTC Vive & $2160 \times 1200$ & $90 \mathrm{~Hz}$. & $110^{\circ}$ & 900.00 \\
\hline Gear VR & $2560 \times 1440$ & $60 \mathrm{~Hz}$. & $96^{\circ}$ & 100.00 \\
\hline Oculus GO & $2560 \times 1440$ & $60 \mathrm{~Hz}$. & $110^{\circ}$ & 169.00 \\
\hline
\end{tabular}

\section{E. Natural User Interfaces (NUI)}

Recent developments in input peripherals are changing the way digital displays, the mouse and the keyboard interact with each other, and are already being replaced by tactile interfaces based on body movement [52]. These recent forms of interaction are part of the evolution of interfaces; computing has evolved, changed and diversified. The term NUI, coined by Mann, explores new forms of human-computer interaction, leaving room for research that focuses on new fields of application. NUI and VR are closely related, as the user, as part of the simulation, is expected to act as if he or she were in the real world; for this reason, one of the best options for interacting with the software is to use NUI. The NUI are a revolution in the world of computing, not because they replace the traditional interfaces that are widely used, but because they contribute to the design of new types of applications and new forms of original and innovative interactions that can be applied in Production, Administration, Marketing, etc.

\section{F. Natural Devices Interaction}

Fig. 3 shows the main devices necessary for the creation of NUI. Microsoft Kinect 2.0 (Fig. 3(a)) is the first to appear for the consumer market, created for entertainment purposes for games controlled through transduction, but then used for more advanced applications. Nimble VR (Fig. 3(b)) focuses only on the recognition of hands. Similar to Nimble VR (Fig. 3(b)), Leap Motion allows immersion using hands, but differs from the others by using two cameras for hand tracking, providing greater accuracy. Manus VR (Fig. 3(d)), unlike the others, uses motion sensors built into gloves.

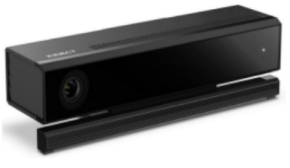

(a)

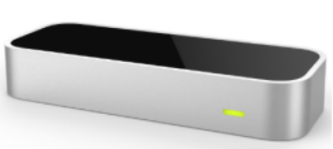

(b)

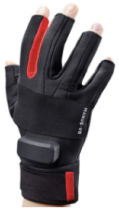

(c)

Fig. 3: Natural Devices Interaction.

Technologies now exist to capture different aspects of a participant's hand, face, and body actions in VR research. However, capturing all aspects of behaviour at the same time remains a challenging problem, and these technical limitations impose critical constraints on what psychology studies can be carried out. Despite the many challenges in the domain of mocap, there are many reasons why we believe that a rich capture of the human behaviour is valuable for social interaction research [53]. The historical review and the establishment of the state of the art allow us to glimpse the enormous potential of the resources and elements of immersive technologies, whose use in marketing strategies will allow innovative and original approaches.

\section{KNOWLEDGe CONSTRUCTION By InMERSION IN IMMERSIVE TECHNOLOGIES}

VR is an emerging technology that allows users to perceive reality through a set of devices that stimulate some sensory organs of a model of a real or fictitious environment. VR provides users with a system of intuitive interaction with the virtual environment and its objects as if they were real, through the possibility of immersion and 3D simulation managed by computer. This system stimulates the understanding of complex systems and allows people to approach diverse and unlimited knowledge and experiences [54]. For Niwhede and Lindgren [55], was not only created to experience games in a 3D environment, but also has great potential for teaching/learning activities in the field of education, as well as in industry, commerce, scientific and technological research and other economic and business activities. Specifically in the field of education, it is possible to create simulated virtual environments, in which students can interact with virtual objects using controllers and interaction devices. In teaching/learning environments, the aim of the use of this technology in principle, is to facilitate and motivate student learning, enabling learning through the creation of experiences in which it is possible to move, interact and understand, 
through the experiences and actions in the virtual world. The design of a learning experience could, of course, also be done in the real world, but there may be physical, temporal, economic and security limitations, among others that may make the virtual world a better option. VR can also be focused to improve students' motivation, which is also an important aspect of teaching/learning activities.

Contemporary computer-based VR systems have a number of sensors, limiting the user's space. This creates a very high differential value compared to smart phone based systems, because they enable closer to reality sensory experiences within virtual space. In one case, a vertical movement of the user implies a similar movement within the virtual world, which allows to perceive a feeling of immersion when sitting on a chair or a carpet placed on the floor. Additionally, there is the possibility of including trackers, in order to position additional elements within the virtual world [56]. Another similar initiative is the Oculus Rift helmet, with very similar quality and functionality.

The absence of symbolic mediation means that there is no implication of the reflection of conscience, which allows for a first-person experience. For the constructivist approach of the Cs. of education, the construction of knowledge requires firstperson experiences, which are those that cannot be completely shared with other individuals Immersive VR allows for firstperson experiences through the elimination of interfaces, which occurs in user-computer interaction. In this aspect, VR is unique. This technology allows a synthetic experience, which allows the capture of the essence of meaning for the person, who participates in order to know the virtual world [57]. These experiences, called Plasticity by Maturana [16], are defined as "the greater or lesser capacity of an organism to adapt to its environment", because they are known as intelligence by other approaches. Learning is understood as a process of accumulation of representations of the environment. Maturana [7] refers to the conditions of recurrence as a continuous process of transformation of behavior through a continuous change in the capacity of the nervous system to synthesize it into behavior that satisfies recurrent demands, classified by the observer as reactive. In this case, the virtual world requires the use of appropriate metaphors and some elements of VR such as transduction, reification, simulation of situations, real characters or even avatars, all of which will allow for original and unforgettable experiences.

VR is becoming an important emerging technology, the use of which can achieve enormous benefits. It is considered as a complete visualization environment using appropriate computer technologies. It is in this context that it offers unique experiences in which the student or user experiences an immersion that allows the perception of a reality through the different senses and, as Winn [6], argues, there are possibilities to expand these experiences through transduction, an experience in which the traditional interfaces between the user and the computer are changed and the user literally "sees the computer", which allows experiences using body movements that interact with the system. It is also possible to transform reality through reification, allowing beaches, oceans, swimming pools, etc. to be seen from various angles and even enlarged or minimized.

The reasons why immersive sensory VR is used as a powerful teaching and training tool are as follows [58]:

- It allows direct experiences of a phenomenon,

- It is three-dimensional,

- It allows experiences with multiple reference frames,

- It enables multisensory communication, and

- It is physically immersive.

A learning theory can be developed to cover a wide range of topics, interests and activities for dealing with complex and abstract issues, which can be enhanced by multisensory "immersion" (considering three-dimensional representations; multiple perspectives and frames of reference; multimodal interfaces; simultaneous visualization, auditory and tactile feedback, and various types of interaction that cannot be performed in the real world).

The illustrative themes applicable to virtual worlds are [58]:

- Multisensory stimuli draw learners' attention to important behaviours and relationships, supporting them for better understanding, through different sensory perspectives, also avoiding interaction errors with the use of feedback stimuli and improving usability.

- New representations and perspectives can help students to improve their ability to correct misconceptions, formed through traditional education, and can also help students to develop correct mental models.

- Enabling multimodal representation (voice commands, gestures, menus, virtual controls, and physical controls) will facilitate usability and appear to enhance learning. Multimodal commands are flexible and allow interaction to be tailored to individual preferences, as well as to distribute attention when performing various learning activities.

- Experiences with students and teachers suggest collaborative learning, which can be implemented with two or more students, who "guide the interaction", "remember observations" and "experience activities" in VR. Extending this to collaboration among multiple students sharing synthetic environments can increase attention and improve learning levels.

Likewise, from the pedagogical perspective, which studies the theory, activities and teaching methods, Marton and Booth describe three aspects of learning, the agent of learning, the act of learning and the object of learning [59]. The agent of learning describes what initiates learning. The act of learning describes the intentions of the learning experience, to memorize or understand something. The object of describes the content, the meaning of the phenomenon being learned. The object of learning can be divided into direct and indirect learning object. The direct learning object is the content of what is being learned and the indirect learning object describes the objective of the act of learning, i.e. the competencies that the learner is expected to develop. In other words, the indirect object and act of learning describes the "how" aspect of learning, while the direct object of learning describes the "what" aspect. Marton and Booth also describe three temporary facets or phases of the learning experience. These three facets are: acquisition, 
knowledge and use of [59]. The learning object can be seen as the link between the three temporary facets.

VR has been used for a long time in educational and training activities, and various simulators have been developed for different types of tasks, such as the operation of airplanes, submarines, power plants, tanks, helicopters, ships, cranes, trains, surgery, automobiles and air traffic control [60]. For Bhat [38], the most common virtual environment used is the 3D environment in various fields, such as: architecture, construction, engineering, etc. 3D visualization allows a better platform for shared and collaborative understanding of each individual in a team. The final users of the application can be people not familiar with technologies, and for them it is necessary to reduce the complexity of the model.

Finally, the different topics covered should be considered for teaching applications, considering the diversity of learner profiles, as well as the learning and thinking styles [4], and the potential of the different hardware and software elements to be used for different types of applications, considering also the costs and technological feasibility for the implementation of these systems, which will undoubtedly contribute in an important way to the teaching/learning activities, and also considering the open problems of immersive technologies.

\section{CONCLUSION AND ReCOMmEndations}

Not only the "autopoiesis theory" and other approaches based on the biology of human cognition, but also most educational theories, suggest that authentic learning takes place in environments that foster first-person experiences since they suppress symbolic mediation and reflection, in addition to capturing the subject's attention, motivating to study and thus reinforcing their learning.

Likewise, in this work, the state of the art of the biological foundations of human cognition of the different approaches of education and of immersive VR has been established, which can allow to take advantage of the enormous potential of this emerging technology, which would make possible the adoption of new approaches, methodologies and techniques for the innovation of human talent education and training practices, since first-person experiences, which are very close to those of the real world, can be a good alternative to consider for the design and development of models of learning teaching systems, which use metaphors that include multisensory actions and perceptions.

The participation of diverse sources of experience is recommended for research in this area, for the conception and development of systems that use immersive technologies and especially the experience of full immersion, requiring the use of working methods for multidisciplinary teams that include specialists in the fields of pedagogy, educational psychology, neurosciences, specialists in the domain of the knowledge they intend to teach, as well as technicians in graphic, artistic, computer, multimedia and project management projects.

It is also advisable to consider the importance of using Artificial Intelligence, which allow teaching and learning systems to be provided with some adaptive characteristics derived from the identification of user profiles, as well as the different environments that may be important and significant.

\section{ACKNOWLEDGMENT}

The authors would like to thank the National University of San Agustín of Arequipa (UNSA) - Peru, and the Federal University of Santa Catarina - Florianopolis - Brazil

\section{REFERENCES}

[1] Luis Alfaro, Claudia Rivera, Jorge Luna-Urquizo. "Using Project-based Learning in a Hybrid e-Learning System Model". International Journal of Advanced Computer Science and Applications, Vol. 10, No. 10, 2019.

[2] Luis Alfaro, Erick Apaza, Jorge Luna-Urquizo, Claudia Rivera. "Identification of Learning Styles and Automatic Assignment of Projects in an Adaptive e-Learning Environment using Project based Learning". International Journal of Advanced Computer Science and Applications, Vol. 10, No. 11, 2019.

[3] A. Flores, Luis Alfaro, Jose Herrera, Edward Hinojosa. "Proposal Models for Personalization of e-Learning based on Flow Theory and Artificial Intelligence". International Journal of Advanced Computer Science and Applications, Vol. 10, No. 7, 2019.

[4] Luis Alfaro, Claudia Rivera, Jorge Luna-Urquizo, Sofia Alfaro, Francisco Fialho. "Virtual Reality Full Immersion Techniques for Enhancing Workers Performance, 20 years Later: A Review and a Reformulation". International Journal of Advanced Computer Science and Applications, Vol. 10, No. 10, 2019.

[5] B.M. Quispe, L.A. Casas, O.A. Oviedo, J.H. Quispe, C.V. Chavez, R.V. Pucho, B.D. Joaquin. "Proceedings of the 10th International Conference on Education Technology and Computers". International Journal of Advanced Computer Science and Applications, pp. 341-346, Tokyo, Japan, 2018.

[6] W. Winn. "A conceptual basis for educational aplications of virtual reality". 1993. http://www.hitl.washington.edu/projects/education/winn/ winn-R-93-9.txt

[7] H. Maturana. "Biology of cognition". Biological Computer Laboratory Research Report BCL 9.0. Urbana IL: University of Illinois, 1970. http: //www.enolagaia.com/M70-80BoC.html

[8] H. Maturana. "Biology of language: The epistemology of reality. psycology and biology of language and thought". New York: academic press, pp. 27-63. 1978. Isbn 0-12-497750-2. http://www.enolagaia.com/ umuarchive/m78bol.html

[9] H. Maturana."Refexiones: Aprendizaje o deriva ontogénica. In: Desde la biología a psicologia." Maturana, Humberto R. Santiago de Chile: Editorial Mitech Ltda. Ediciones Synthesis, 1993. p. 82-102. ISBN: 9567335-01-X

[10] H. Maturana, F. Varela. "De máquinas y seres vivos - una teoría sobre la organización biológica." Chile. Editorial Universitaria S.A. 1972.

[11] H. Maturana, F. Varela."El árbol del conocimiento." Octava Edición. Santiago de Chile. Editorial Universitaria. 1992.

[12] Ch. Chauhan, M. Ul Akram. Knowledge Management, Sustainable Business Performance and Empowering Leadership: A Firm-Level Approach. International Journal of Knowledge Management, Volume 15, Issue 2, April-June 2019

[13] K. Dampney's, D. Richards, P. Busch. The Meaning of Tacit Knowledge. Article in Australasian Journal of Information Systems, January 2007, DOI: 10.3127/ajis.v10i1.438.

[14] Bojan Obrenovic, Slobodan Obrenovic, Akmal Hudaykulov. The Value of Knowledge Sharing: Impact of Tacit and Explicit Knowledge Sharing on Team Performance of Scientists. International Journal of Management Science and Business Administration, Vol. 1, No. 2, Pages 33-52, 2015.

[15] P. Razeto-Barry. "Autopoiesis 40 years Later. A Review and a Reformulation." in Origins of Life 42(6). October 2012. DOI: 10.1007/s11084012-9297.

[16] H. Maturana, G. Guiloff. "En búsqueda de la inteligencia de la inteligencia." Santiago de Chile. Editorial Mitech Ltda. Ediciones Synthesis. 1992. pp. 59-81.

[17] M. Mahmoodi-Shahrebabaki. Vygotsky, Education, and Literacy. Unpublished manuscript, Department of Literacy Studies, Middle Tennessee State University. February 2019 DOI: 10.13140/RG.2.2.19109.76003 
[18] F. Flores, W. Terry. Hacia la comprensión de la informática y la cognicioń. Ordenadores y conocimiento para el diseno del siglo XXI. Barcelona. Editorial Hispano Europea. S.A. 1989. pp. 266.

[19] M. Starks. Review of 'Philosophy in a New Century' by John Searle (2008) (review revised 2019). In book: The Logical Structure of Philosophy, Psychology, Mind and Language in Ludwig Wittgenstein and John Searle - Articles and Reviews 2006-2019 2nd Edition Michael Starks, Publisher: Reality Press, pp. 425-444.

[20] Baktir, Hasan. Speech act theory; Austin and Searle: Derrida's response and Deleuze's Theory of Order-word. Language, Literature and Cultural Studies. V. 202-211. 10.21533

[21] M. Soler, R. Flecha. "From Austin's speech acts to communicative acts. Perspectives from Searle, Habermas and CREA.” Revista Signos. 2010 / 43 Número Especial Monográfico No 2 363-375. 2010. http://dx. doi.org/10.4067/S0718-09342010000400007

[22] K. Karlgren, R. Ramberg, H. Artman. Designing interaction: How do interaction design students address interaction?. Int J Technol Des Educ. 2016. 26: 439. https://doi.org/10.1007/s10798-015-9314-3.

[23] L. Aguilar. Conductismo radical de B.F. Skinner: coordenadas ontoepistemológicas y visión del ser humano. CONHISREMI, Revista Universitaria de Investigación y Diálogo Académico, Vol. 14, No. 2, 2015.

[24] S. Lyons, Z. Berge. Social Learning Theory. In: Seel N.M. (eds) Encyclopedia of the Sciences of Learning. Boston MA: Springer. 2012

[25] V. Melo. Emancipatory Education and Youth Engagement in Brazil: A Case Study Bridging the Theory and Practice of Education for Social Transformation. Educ. Sci. 2019, 9(1), 23; 2019. https://doi.org/10.3390/ educsci 9010023

[26] S. Abbasnasab, M. Mohd. Sociocultural Perspective on Assessment for Learning: The Case of a Malaysian Primary School Procedia. The 8th International Language for Specific Purposes (LSP) 2012 doi: 10.1016/j.sbspro.2012.11.277.

[27] Lilik Untari. An epistemological review on humanistic education theory Jurnal Bahasa Dan Sastra. Volume 1 Nomor 1 Januari-Juni 2016. P-ISSN 2527-8088. E-ISSN: 2527-807X.

[28] G. Aikenhead. Review of Research on Humanistic Perspectives in Science Curricula. A paper presented at the European Science Education Research Association (ESERA) 2003 Conference, Noordwijkerhout, The Netherlands, August 19-23, 2003.

[29] Verden-Zöller, Gerda. El juego en la relación materno infantil: Fundamento biológico de la conciencia de si mismo y de la conciencia social. In: Amor y Juego. Fundamentos olvidados de lo humano. Maturana, Humberto R. e Verden-Zöller, Gerda. Santiago de Chile: Editorial Instituto de Terapia Cognitiva, 1994. p. 71-136. ISBN: 956-7344-01-9.

[30] Maturana, Humberto R. Emociones y lenguaje en educación y política. Sexta edición. Santiago de Chile: Editorial Universitaria, 1992. pp. 98.

[31] P. Pérez. Revisión de las teorías del aprendizaje más sobresalientes del siglo XX. Tiempo de Educar, vol. 5, núm. 10, julio-diciembre, 2004, pp. 39-76.

[32] W. Arias. Jerome Bruner 100 años dedicados a la psicología la educación y la cultura. Rev. peru. hist. psicol. / ISSN 2414-195X / Vol 1 / Enero - Diciembre 2015 / pp. 59-79.

[33] J. Olivo-Franco, Dewey, Freire, Humberto Maturana. Educación y democracia una década pendiente en Latinoamérica. DELECTUS. Revista de Capacitación y Educación Continua. 2(1), 9-28. 2019

[34] A. Alanazi. Critical Review of Constructivist Theory and the Emergence of Constructionism. American Research Journal of Humanities and Social Sciences (ARJHSS). Volume 2, 8. Pag. 2019.

[35] Chronis Kynigos. Constructionism: theory of learning or theory of design?. 12th International Congress on Mathematical Education. 8 July - 15 July, 2012, COEX, Seoul, Korea.

[36] R. Jafari, H. Davatgari. Review of Constructivism and Social Constructivism. Journal of Social Sciences, Literature and Languages. Vol. 1(1), pp. 9-16, 30 April, 2015.

[37] Jorge Martín-Gutiérrez, Carlos Efrén Mora, Beatriz Añorbe-Díaz, Antonio González-Marrero. "Technologies Trends in Education. " EURASIA Journal of Mathematics Science and Technology Education ISSN 13058223 (online) 1305-8215 (print) 2017 13(2):469-486 DOI 10.12973/eurasia.2017.00626a.
[38] Akrati Bhat, Gunjan Bhagwat, Jagannath Chavan. A Survey on Virtual reality platform and its Applications International Journal of Advanced Research in Computer Engineering \& Technology (IJARCET), vol. 4, number 10, 2015.

[39] Alqahtani, A. S., Daghestani, L. F., Ibrahim, L. F. "Environments and system types of virtual reality technology in stem: a survey". International Journal of Advanced Computer Science and Applications (IJACSA), 8(6), 2017.

[40] Daghestani, L. The design, implementation and evaluation of a desktop virtual reality for teaching numeracy concepts via virtual manipulatives. Doctoral dissertation, University of Huddersfield. 2013.

[41] N. Menck, X. Yang, C. Weidig, C. Winkes, C. Lauer, H. Hagen, B. Hamann and J. Aurich, "Collaborative factory planning in virtual reality," Procedia CIRP, vol. 3, p. 317-322, 2012.

[42] N. Sala. "Multimedia and $V R$ in architecture and in engineering education". In Proceedings of the 2nd WSEAS/IASME International Conference on Educational Technologies, Bucharest, Romania, vol. 22, 2006.

[43] J. Psotka, "Immersive formatiom systems: Virtual reality and education and formatiom," Instructional science, vol. 23, no. 5, p. 405-431, 1995.

[44] Luis Alfaro, Claudia Rivera, Juan Zuñiga, Alonso Portocarrero, Jorge Luna-Urquizo, Alberto Barbosa. "Immersive Technologies in Marketing: State of the Art and a Software Architecture Proposal". International Journal of Advanced Computer Science and Applications, Vol. 10, No. 10, pp. 482-490, 2019.

[45] G. Calle, Eveling Castro-Gutierrez, Luis Alfaro. "Virtual Rehabilitation Using Sequential Learning Algorithms". International Journal of Advanced Computer Science and Applications, Vol. 9, No. 11, 2018.

[46] J. Juang, W. Hung, S. Kang, "Simcrane 3d+: A crane simulator with kinesthetic and stereoscopic vision," Advanced Engineering Informatics, vol. 27, no. 4, p. 506-518, 2013.

[47] R. Linares, "Exploración de artículos científicos con realidad virtual y procesamiento del lenguaje natural," Maestría en Ing. Informática. Escuela de Posgrado. Universidad Nacional de San Agustín de Arequipa., 2017.

[48] Luis Alfaro, Ricardo Linares, José Herrera. "Scientific Articles Exploration System Model based in Immersive Virtual Reality and Natural Language Processing Techniques." Article Published in International Journal of Advanced Computer Science and Applications(IJACSA), Volume 9 Issue 7, 2018. DOI :10.14569/IJACSA.2018.090736.

[49] B. Zohra, G. Fabrice, R. Paul, B. Julien and P. Fabien, "An Overview of Interaction Techniques and 3D Representations for Data Mining," Applications of Virtual Reality, p. 185, 2012.

[50] L. Rapanotti and J. G. Hall, "Design concerns in the engineering of virtual worlds for learning", Behaviour \& Information Technology, vol. 30, no. 1, pp. 27-37, 2011

[51] K. Wanarat and T. Nuanwan, "Using 3d visualisation to improve public participation in sustainable planning process: Experiences through the creation of koh mudsum plan, thailand," Procedia-Social and Behavioral Sciences, vol. 91, p. 679-690, 2013.

[52] A. Cámara, "Natural user interfaces," in In IFIP Conference on HumanComputer Interact, 2011.

[53] X. Pan. A. Hamilton. "Why and how to use virtual reality to study human social interaction: The challenges of exploring a new research landscape. " British Journal of Psychology (2018), 109, 395-41, 2018.

[54] L. Alfaro. "Contribuições para a modelagem de um ambiente inteligente de educação baseado em realidade virtual," Doutorado. Programa de Pós-Graduação em Engenharia de Produção. Universidade Federal de Santa Catarina, Brasil, 1999.

[55] J. Niwhede and A. Lindgren. "VR from a Learning Perspective. " Masther Thesis: Department of Design Sciences. Faculty of Engineering. Lund University. 2017

[56] H. Skouteris, S. Edwards, H. Morris, R. Cox, L. Baur, L. Wolfenden and T. Huang, "Early childhood education and health working in partnership: the critical role early childhood educators can play in childhood obesity prevention," Early Child Development and Care, vol. 187, no. 8, pp. 1239-1243, 2017.

[57] F. Balan, "Marketing Experiencial". Tesis de grado. Administración y Dirección de Empresas", F. de Cs. Sociales y Jurídicas. Universidad Miguel Hernandez de Elche., Alicante. España, 2015. 
[58] C. Dede, M. Salzman, C. Loftin, R. Bowen. "ScienceSpace: Virtual realities for learning complex and abstract scientific concepts" 1995. http://www.virtual.qmu.edu/vriaspdf.htm.

[59] F. Marton and S. Booth, "Learning and Awareness. "Lawrence
Erlbaum Associates, Inc., Publishers, 1997.

[60] W. Jin, "VR technology in the design of the space environment research, " in Control, Automation and Systems Engineering (CASE), 2011 International Conference on, 2011, pp. 1-4. 